\title{
Saphenous nerve innervation of the medial ankle
}

\author{
This article was published in the following Dove Press journal: \\ Local and Regional Anesthesia \\ 5 March 2013 \\ Number of times this article has been viewed
}

\author{
Steven R Clendenen' \\ Joseph L Whalen ${ }^{2}$ \\ 'Department of Anesthesiology, \\ ${ }^{2}$ Department of Orthopedic Surgery, \\ Mayo Clinic, Jacksonville, FL, USA
}

Correspondence: Steven R Clendenen Department of Anesthesiology, Mayo Clinic, 4500 San Pablo Road, Jacksonville, FL 32224, USA

Tel + I 9049563327

Fax + I 9049563332

Email clendenen.steven@mayo.edu
Background: The distal saphenous nerve is commonly known to provide cutaneous innervation of the medial side of the ankle and distally to the base of the great toe. We hypothesize that the saphenous nerve innervates the periosteum of the medial malleolus and joint capsule.

Methods: Five fresh limbs were dissected and the saphenous nerve was traced distally with magnification. The medial malleolus, talus, and soft tissue were fixed in formaldehyde, decalcified, and embedded in paraffin and sectioned. Histologic slides were then prepared using S100 antibody nerve stains.

Results: Histologic slides were examined and myelinated nerves could be observed within the medial capsule and periosteum in all the specimens.

Conclusion: We have demonstrated that the saphenous nerve innervates the periosteum of the medial malleolus and joint capsule.

Keywords: saphenous nerve, innervation, medial ankle

\section{Introduction}

The saphenous nerve is commonly known to contribute to the sensory innervation of the lower extremity. The medical and anatomic literature describes the saphenous nerve as providing sensory innervation of the medial leg and calf, terminating distally at the "ball" of the great toe. ${ }^{1-5}$ The importance of this nerve providing sensory supply to the medial ankle area appears to be underappreciated. One anatomic study ${ }^{6}$ of the nerve supply to the ankle joint concluded that the saphenous nerve along with the tibial, superficial, deep peroneal, and sural nerves provide the articular branches.

The saphenous nerve is classically described in most anatomic texts as the longest branch of the femoral nerve. It arises from the femoral nerve in the femoral triangle and descends laterally to the femoral vessels to enter the adductor canal. The nerve then crosses the femoral vessels to lie on their medial side at the distal portion of the adductor magnus muscle. It then pierces the sartorial fascia between the sartorius and gracilis tendons just above the medial aspect of the knee and becomes subcutaneous thereafter, giving rise to the infrapatellar branch supplying the skin over the anterior inferior knee, and may form communication with the anterior cutaneous branches of the femoral nerve. Below the infrapatellar branch, the saphenous nerve provides the medial crural nerves that supply cutaneous innervation to the anterior and medial leg. Below the knee, the saphenous nerve follows the course of the greater saphenous vein to the medial side of the ankle and foot, and is said to terminate as far as the medial 
aspect of the first metatarsal head. It is understood that there is often variability in the terminal cutaneous branches. Mercer et $\mathrm{al}^{7}$ and Kosinski ${ }^{8}$ found in 19 and 96 specimens, respectively and combined, only one instance of the nerve extending to the medial first metatarsophalangeal joint.

Although cursory descriptions of the saphenous nerve anatomy as it approaches the ankle have been described, ${ }^{7-9}$ the importance of its distribution at the ankle appears to be lacking regarding possible sensory innervation of the ankle joint. Approximately $3 \mathrm{~cm}$ proximal to the tip of the medial malleolus, the nerve is said to divide into anterior and posterior branches in relation to the saphenous vein. ${ }^{7}$ These branches are then described to terminate in the integument over the medial malleolus, while the saphenous vein continues into the foot.

In our clinical experience with regional anesthesia, popliteal block alone does not provide adequate coverage for surgery or postoperative pain management following major ankle surgeries, including arthrodesis, arthroplasty, and fractures. When the addition of a saphenous nerve block is performed following foot and ankle surgery, we have found the pain relief to be excellent (American Orthopaedic Foot \& Ankle Society, unpublished data, 2009).

The purpose of this study was to correlate our clinical experience with anatomic and histologic evidence of the bone and medial ankle joint capsule innervation by the saphenous nerve.

\section{Materials and methods}

This study was reviewed and approved by the institutional review board at the Mayo Clinic. Five fresh limbs, devoid of pathology in the foot or ankle, were obtained after surgical amputation through the proximal tibia or knee to perform dissections of the saphenous nerve supply to the foot. The nerve was traced distally with the aid of a dissecting microscope or loupe magnification, and particular attention was paid to the nerve divisions at and just below the medial malleolus. Demonstration of the nerve fibers from the saphenous nerve in the ankle capsule was carried out by resecting a block of the medial malleolus and talus with the medial ankle mortise and its soft tissue. The specimen was fixed in formalin, decalcified (Fisher Scientific, Hampton, NH), and embedded in paraffin to allow serial sections. Histologic slides were then prepared using S100 antibody nerve stains (Dako North America, Carpinteria, CA). S100 protein is a highly sensitive marker for myelinated nerves in the peripheral nervous system. S100 monoclonal antibody is directed against a calcium-binding protein present in the nucleus and cytoplasm of Schwann cells. ${ }^{10}$

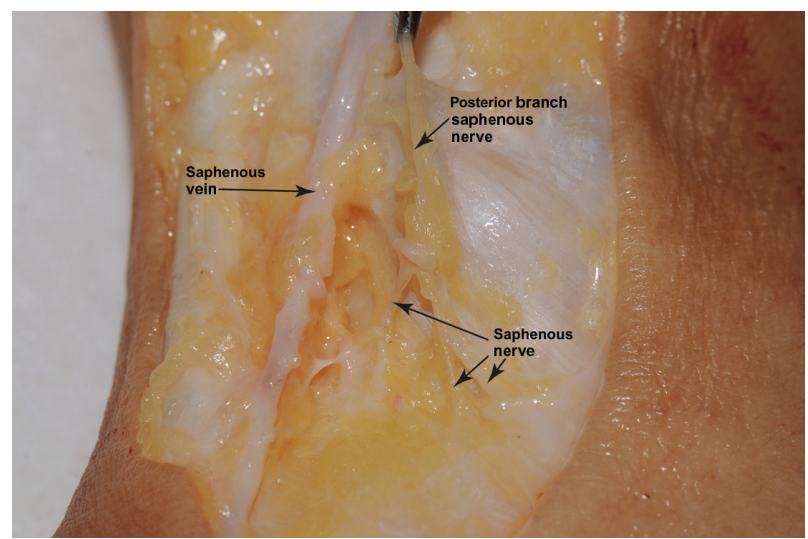

Figure I Gross dissection of medial ankle.

\section{Results}

\section{Findings of dissection and histology}

At the mid level of the tibia, the saphenous nerve was observed to divide into two or more branches that gave rise to additional nerves supplying the skin and subcutaneous tissues. Near the medial supramalleolar region, we found a consistent division of the nerve into branches that were anterior and posterior to the greater saphenous vein. The posterior branch terminated into several fine nerves just below the medial malleolus that macroscopically attached to the ankle capsule and deltoid ligament (Figure 1). The anterior branch appeared to course over the medial anterior ankle and terminated in the subcutaneous tissues. In none of the specimens was there an identifiable nerve following the vein into the medial foot.

Photographs of the sectioned block (Figure 2) and photomicrographs of the slides were examined for orientation. In the histologic slides, we could identify fine branches of the

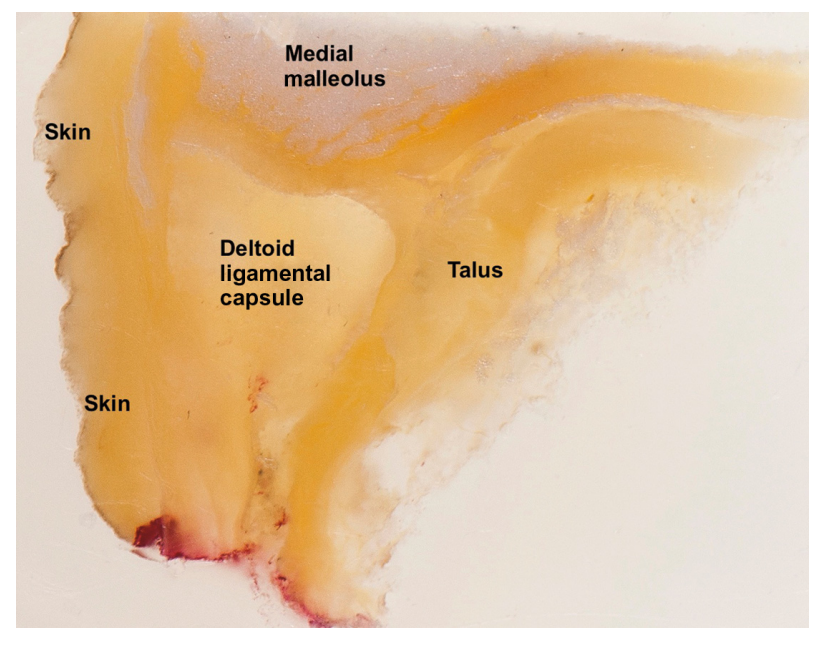

Figure 2 Paraffin-embedded specimen of medial ankle. 


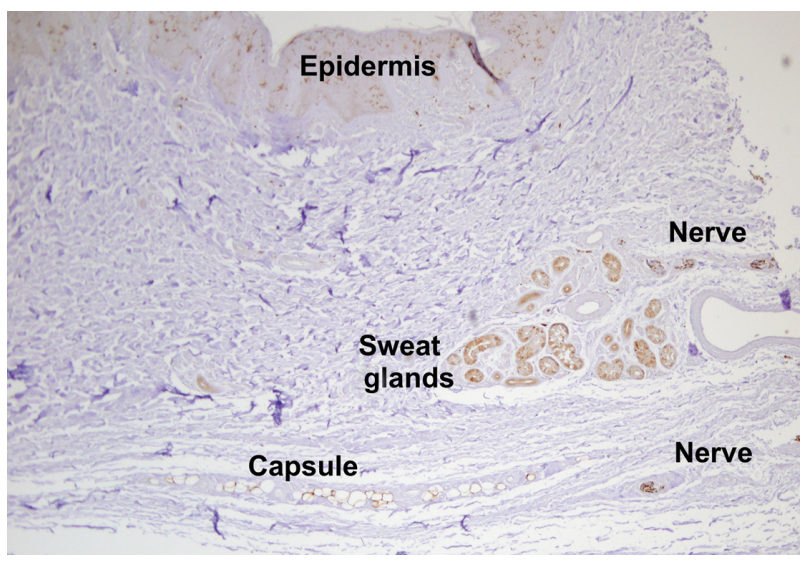

Figure 3 Photograph of histologic slide of saphenous nerve in the joint capsule.

saphenous nerve within the medial capsule and periosteum in all the specimens (Figures 3 and 4).

\section{Discussion}

We have verified histologically that the saphenous nerve innervates the periosteum of the medial malleolus and joint capsule. Gross anatomic studies by Sarrafian confirmed variations of the saphenous nerve to the periosteum of the distal tibia, medial malleolus, and joint capsule. ${ }^{11}$ Our results correlate with the findings of Blumenthal et al of improved dynamic pain scores with addition of a continuous femoral catheter to a continuous popliteal sciatic catheter following major ankle surgery. ${ }^{12}$ The importance of the saphenous nerve innervating the medial ankle is overlooked in the anesthesia literature. We recognize that patients frequently have significant medial pain following ankle joint surgery. Our current practice for analgesia following these ankle procedures is to place both a popliteal

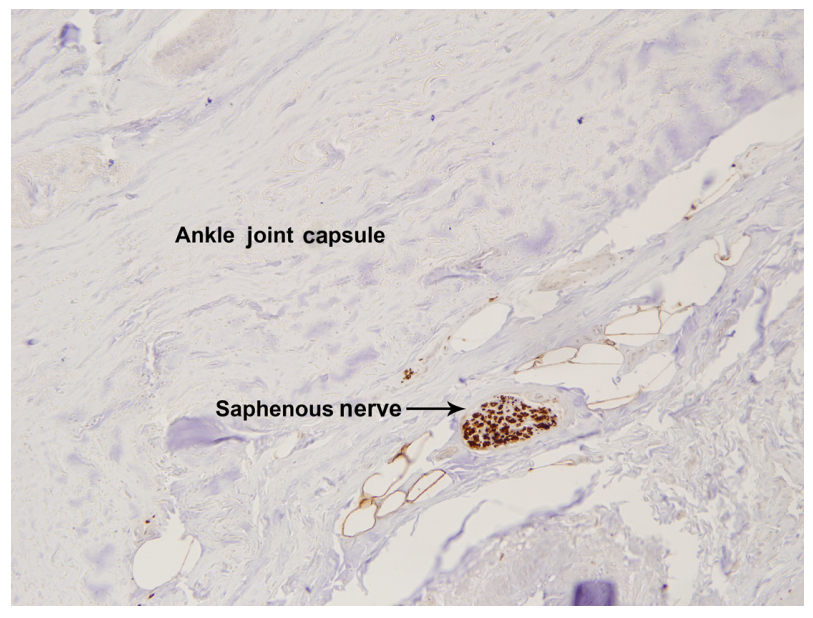

Figure 4 Photograph of histologic slide of saphenous nerve in the periosteum, 40x. and saphenous nerve catheter. We place our saphenous blocks distally to the adductor canal in an effort to avoid the motor branch to the vastus medialis, as described by Kapoor et al. ${ }^{13}$

In conclusion, the distal saphenous nerve is a cutaneous branch to the medial ankle and forefoot, and also innervates the periosteum of the medial malleolus and medial joint capsule. Block of the saphenous nerve, in addition to the sciatic nerve, is essential for complete anesthesia and analgesia of the hind foot and ankle.

\section{Acknowledgments}

The authors would like to acknowledge Pamela A Kreinest for slide preparation. Financial support was provided by the Mayo Clinic, Jacksonville, FL.

\section{Disclosure}

The authors report no conflicts of interest in this work.

\section{References}

1. Hadzic A. Textbook of Regional Anesthesia and Acute Pain Management. New York, NY: McGraw-Hill Professional; 2006.

2. Craig EJ, Clinchot DM. Femoral neuropathy. In: Frontera WR, Silver JK, Rizzo TD, editors. Essentials of Physical Medicine and Rehabilitation, 2nd ed. Philadelphia, PA: Saunders Elsevier; 2008.

3. Wedel DJ, Horlocker TT. Nerve blocks. In: Miller RD, editor. Miller's Anesthesia, 7th ed. Philadelphia, PA: Churchill Livingstone Elsevier; 2010.

4. Canale ST, Beaty JH. Campbell's Operative Orthopaedics. Philadelphia, PA: Mosby Elsevier; 2008.

5. Marx J, Hockberger R, Walls R. Rosen's Emergency Medicine Concepts and Clinical Practice. Philadelphia, PA: Mosby Elsevier; 2010.

6. Mentzel M, Fleischmann W, Bauer G, Kinzl L. Ankle joint denervation. Part 1. Anatomy: the sensory innervation of the ankle joint. Foot Ankle Surg. 1999;5:15-20.

7. Mercer D, Morrell NT, Fitzpatrick J, et al. The course of the distal saphenous nerve: a cadaveric investigation and clinical implications. Iowa Orthop J. 2011;31:231-235.

8. Kosinski C. The course, mutual relations and distribution of the cutaneous nerves of the metazonal region of leg and foot. $J$ Anat. 1926;60:274-297.

9. Huelke DF. The origin of the peroneal communicating nerve in adult man. Anat Rec. 1958;132:81-92.

10. Gonzalez-Martinez T, Perez-Pinera P, Diaz-Esnal B, Vega JA. S-100 proteins in the human peripheral nervous system. Microsc Res Tech. 2003;60:633-638.

11. Sarrafian SK, Kelikian AS. Sarrafian's anatomy of the foot and ankle. In: Kelikian AS, editor. Sarrafian's Anatomy of the Foot and Ankle, 3rd ed. Philadelphia, PA: Lippincott Williams \& Wilkins; 2011.

12. Blumenthal S, Borgeat A, Neudorfer C, Bertolini R, Espinosa N, Aguirre J. Additional femoral catheter in combination with popliteal catheter for analgesia after major ankle surgery. Br JAnaesth. 2011;106: 387-393.

13. Kapoor R, Adhikary SD, Siefring C, McQuillan PM. The saphenous nerve and its relationship to the nerve to the vastus medialis in and around the adductor canal: an anatomical study. Acta Anaesthesiol Scand. 2012;56: 365-367. 


\section{Publish your work in this journal}

Local and Regional Anesthesia is an international, peer-reviewed, open access journal publishing on the development, pharmacology, delivery and targeting and clinical use of local and regional anesthetics and analgesics. The journal welcomes submitted papers covering original research, basic science, clinical studies, reviews \& evaluations,

guidelines, expert opinion and commentary, case reports and extended reports. The manuscript management system is completely online and includes a very quick and fair peer-review system, which is all easy to use. Visit http://www.dovepress.com/testimonials.php to read real quotes from published authors.

Submit your manuscript here: http://www.dovepress.com/local-and-regional-anesthesia-journal 